\title{
O MOVIMENTO NEGRO E AS REVOLUÇõES DE 1968: UMA ANÁLISE DA RELAÇÃO E RESSIGNIFICAÇÃO DO NEGRO E O HISTÓRICO DO MOVIMENTO NO BRASIL
}

\author{
THE BLACK MOVEMENT AND THE 1968 REVOLUTIONS: AN ANALYSIS OF THE RELATION AND \\ RESIGNIFICATION OF THE BLACK AND THE HISTORY OF MOVEMENT IN BRAZIL
}

Mariana Morena PEREIRA ${ }^{1}$

Artigo recebido em 16/03/2019 e aceito em 22/07/2019

Palavras-chave: Movimento Negro, Revoluções de 1968 nos EUA,

Movimentos Sociais, Brasil.

\section{Keywords:}

Black Movement, 1968 Protests in U.S, Social Movements, Brazil.

\section{R E S U M O}

As Revoluções de 1968 foram um divisor de águas na forma como os movimentos sociais se organizam e se mobilizam ao redor de todo o mundo. 0 surgimento de novas tecnologias promoveu a difusão de táticas de mobilização e pautas contestatórias. Nesse sentido, a partir de 1968, se dá início um processo de revolução não só no ambiente social e institucional, mas também nos modelos cognitivos dos indivíduos. 0 movimento negro nos Estados Unidos, em especial, possui papel primordial na difusão de táticas contestatórias na sociedade estadunidense em resposta ao sistema de segregação institucionalizada. 0 presente artigo tem como objetivo analisar o papel que o movimento negro dos EUA iniciado em 1968 teve no Brasil. Observa-se que, apesar de tardio, os protestos sociais chegam ao Brasil e transformam profundamente a comunidade negra e a forma como essa se enxerga na sociedade, possibilitando mudanças estruturais do Estado brasileiro no que tange o reconhecimento de estruturas discriminatórias e na promoção de políticas públicas para a população afrodescendente.

\begin{abstract}
A B S T R A C T
The 1968 Protests were a watershed in the way social movements organized and mobilized around the world. The emergence of new technologies has promoted the spread of mobilization tactics and contesting agendas. In this sense, from 1968, a process of promoting a revolution begins not only in the social and institutional environment, but also in the cognitive models of individuals. The Black Movement in the United States, in special, played a major role once it was able to spread some contesting tactics in US society as a response to the system of institutionalized segregation. This article aims to analyze the role that the US Black Movement had in Brazil. Despite being late, social protests come to Brazil and profoundly transform the black community and the way it sees itself in society, enabling structural changes in the Brazilian state regarding the recognition of discriminatory structure and the promotion of policies for the African descent population.
\end{abstract}

\section{INTRODUÇÃo}

O ano de 1968 é compreendido como um divisor de águas nas formas como os movimentos sociais se organizam e se difundem. Nesse período ocorreu um constante intercâmbio de táticas de ação coletivas nas diversas demandas sociais por mudanças tomando um nível mundial. Assume-se

\footnotetext{
1Bacharela em Relações Internacionais, Universidade Federal do Pampa (2017). Estudante de mestrado no Departamento de
} Ciência Política DCP/FFLCH. Universidade de São Paulo. E-mail: mariana_morena30@hotmail.com. 
que o período de estabilidade entre 1945 a 1968 proporcionou um rearranjo da ordem capitalista e expansionista no sistema mundial. Isso também permitiu que as distintas sociedades passassem a reconsiderar seu papel como indivíduos e contestar modelos institucionais, políticos e sociais predominantes. Afirma-se que as revoluções que ocupam a arena internacional após o ano de 1968 tem como papel de contestar os próprios modelos cognitivos do status quo predominante. Assim, assume-se que a década de 1960 é tomada por diversas manifestações dos movimentos sociais de insatisfações das formas de poder, pela resistência contra sistemas patriarcais, racistas e autoritários que predominavam a nível global. Uma nova esquerda emerge buscando contestar a antiga e endereçar novas questões e atores para se pensar a mudança. Nesse sentido, a luta contrahegemônica não deveria se preocupar apenas com a questão da classe e trabalho, mas em especial, com as formas de existência dentro da sociedade. Buscava-se visibilidade em novas formas de pensar e agir e é, nesse sentido, que movimentos como o feminista, sindical, estudantil e negro insurgem e subvertem.

O Movimento Negro torna-se foco do presente artigo uma vez que este se tornou propulsor de muitos outros movimentos iniciados na década de 1960. A ação coletiva utilizada por várias organizações e as demandas contra o sistema de segregação racial nos Estados Unidos foi elementar para influenciar a mobilização de outros movimentos sociais pelo mundo. Portanto, é necessário entender as principais demandas desse movimento bem como sua organização e influência ocorreu. Dessa análise, busca-se compreender o Movimento Negro no Brasil e contrastar suas principais diferenças em relação ao movimento norte-americano: notadamente a institucionalização da discriminação, no primeiro, e o mito da democracia racial, no segundo. Assume-se que, apesar de tais diferenças, a qual no caso brasileiro retardou a mobilização em massa das organizações, o Movimento Negro se alicerça nas mesmas reivindicações para a população negra: internamente se busca a ressignificação do negro nas várias vertentes da vida social e cultural; externamente se contestam as estruturas segregacionistas e se exigem mudanças nas estruturas formais do Estado, de modo a abolir o racismo institucional e promover políticas públicas que forneçam a igualdade de oportunidades aos negros na sociedade.

Nesse sentido, o presente trabalho se preocupa em trazer à tona as seguintes questões: como relacionar as conquistas do Movimento Negro no Brasil - que resultou em diversas políticas públicas e maior comprometimento do Estado brasileiro com a pauta da igualdade racial e igualdade de oportunidade para negros e negras - com a revolução de 1968? Em suma, o que o movimento de 1968 representa para as conquistas do Movimento Negro no Brasil? Como hipótese a ser confirmada ao longo da pesquisa, nota-se que 1968 representa a subversão, a insatisfação e a demanda por mudanças de instituições e estruturas cognitivas. A partir dessas premissas, assume-se que o Movimento Negro no Brasil é influenciado por grande parte dessas ideias e promove uma mobilização na sociedade gerando o despertar da comunidade negra para sua situação na sociedade 
brasileira. 0 resultado disso, depois de décadas de demandas e reivindicações, foi o início de políticas públicas que buscam atenuar as estruturas de segregação da população afrodescendente na sociedade brasileira. Além disso, entende-se que a onda de contestações a partir de 1968 também influenciou o autorreconhecimento e afirmação de negros e negras, suas culturas e raízes africanas no Brasil.

0 artigo se divide em três partes: a primeira busca esclarecer, em termos gerais, o que foi o Movimento de 1968, bem como entender quais premissas se baseavam as mudanças cognitivas e de comportamento das sociedades ao redor do mundo. Posteriormente, buscou-se entender o movimento negro dos Estados Unidos, visto que o Movimento para os Direitos Civis promoveu grande difusão de táticas de mobilização em nível global, ao conquistar diversos direitos dos indivíduos anteriormente segregados pela estrutura do Estado. Igualmente relevante foi o movimento Black Power, ocorrido partir de 1960, como uma mobilização de suma importância para a compreensão da ressignificação e insurgência da comunidade negra na sociedade estadunidense. Destas considerações busca-se, na terceira parte, entender como esse movimento chegou ao Brasil e também a conjuntura que retardou as reivindicações por direitos na sociedade brasileira. Para tanto, é necessário traçar um histórico de organização do Movimento Negro no Brasil, o qual surge incipiente logo após a abolição da escravatura. É importante entender a evolução dessa mobilização com o passar das décadas. Por fim, conclui-se o presente trabalho buscando-se retornar ao questionamento inicial: o movimento no Brasil é afetado pelas revoluções de $1968 ?$

\section{QUE FOI O MOVIMENTO DE 1968?}

0 ano de 1968 e as revoluções que se desdobraram a partir de maio e junho são divisores de água para se compreender as mudanças de uma perspectiva global não só na organização de relações institucionais e cognitivas da época, mas também da configuração dos movimentos sociais nos dias atuais. Kurlansky (2005) afirma que em 1968 ocorreu uma combustão simultânea entre nações culturalmente distintas - como Polônia, França, Estados Unidos e México - de modo que várias rebeliões irromperam nesses países, carregando como uma das maiores contestações a necessidade da mudança de ideias, de formas de poder e instituições estabelecidas. Assim, as rebeliões de 1968 contestam o status quo institucional e cultural de várias realidades ao redor do mundo.

Nas sociedades industriais Ocidentais, em especial, o ano de 1968 representou o ápice de protestos que questionavam as instituições democráticas, partidos políticos e a ordem mundial do pós-guerra. De acordo com Holtey (2014), nos Estados Unidos o movimento começa em 1964 com o Free Speech Movement; na Alemanha, em 1966, com a formação de uma oposição extraparlamentar 
paralela ao governo de coalizão; na França, em 1968 a ação de estudantes e movimentos trabalhistas afetaram profundamente a sociedade e o regime do então presidente Charles de Gaulle; na Itália, protestos estudantis e greves em massa da classe trabalhadora marcaram o período Hot Autumn, em 1969.

0 período de 1945 a 1968 foi marcado por uma profunda estabilidade na ordem mundial devido à expansão da ordem capitalista e o fim da Segunda Guerra Mundial. Os Estados Unidos se estabeleceram como uma hegemonia mundial na esfera econômica, política e cultural. 0 sistema de alianças construído com a Europa Ocidental e Japão assinalou a liderança das economias capitalistas pela reconstrução de países desenvolvidos. No contexto do conflito bipolar da Guerra Fria, os EUA e União Soviética (URSS) concordaram em preservar a estabilidade por meio de zonas de dominação política - acordo promovido na Conferência de Yalta, realizada em 1945. A liderança mundial norteamericana também teve seus reflexos na descolonização da Ásia e África, relativamente moderada em relação aos conflitos entre as colônias e suas metrópoles (WALLERSTEIN; ZUKIN, 1989). Na França, em especial, o período entre 1950 e 1960 é marcado por evidente estabilidade devido ao que Bihr (2008) chamou de enquadramento da formação social francesa, isto é, a inserção da sociedade no modelo fordista tanto em setores públicos como privados, implantado no regime gaullista, o qual deu impulso a modernização da França nessas décadas.

Nota-se, todavia, que é a própria estabilidade política e econômica gerada pelo período anterior que abre espaço para os movimentos de contestação de 1968. Para Bihr (2008) o Fordismo, que aporta valores ligados a modernização, racionalização e democratização, não é acompanhado no plano político e social francês da época. Isso significa que esse enquadramento e suas gerações mais jovens - nascidas no pós-guerra e que farão parte do movimento estudantil de 1960 - não encontraram determinados valores na sociedade que faziam parte. Isso ocorreu, em grande parte, devido à aliança hegemônica entre a grande burguesia e classes tradicionais criada no regime de De Gaulle no plano sociopolítico. Nesse sentido, o plano sociocultural fordista, exaltava-se uma autonomia individual ampliada que, em contrapartida, não era percebida no plano de relações políticas e ao nível do Estado e instituições devido a predominância de valores e normas éticas e políticas predominantemente religiosas. Nesse sentido, os valores "tradicionais" ressaltavam o amor ao trabalho, à figura do homem (pai) autoritário, responsável e representante do núcleo familiar, a subordinação de esposas e filhos à figura masculina, à repressão da sexualidade fora do casamento, etc.

No mesmo sentido, no plano internacional, o padrão hegemônico estabelecido pelos países Ocidentais também passou a ruir pelo seu próprio sucesso. Alguns fatores importantes contribuíram para isso: (a) a reconstrução dos aliados dos Estados Unidos devido ao Plano Marshall tornou-se tão bem sucedida que viabilizou uma maior autonomia política e econômica a esses Estados; (b) a morte de Stalin marcava, nesse contexto, o fim de um bloco Soviético monolítico; e, (c) as concessões feitas 
durante a década de 1950 para grupos minoritários nos Estados Unidos e países desenvolvidos do Ocidente, acentuaram expectativas que não eram observadas na realidade política, social e econômica de tais países (WALLERSTEIN; ZUKIN, 1989). A partir da década de 1960, portanto, essa configuração de fatores faz insurgir uma onda de contestações, as quais passaram, a partir de então, a questionar esse status quo e protestar por mudanças. Outros fatores-chave para se compreender as rebeliões desencadeadas nessa época se devem ao desenvolvimento de meios de comunicação - a televisão, em especial, passou a conectar espectadores de regiões de todo mundo - e do modernismo em si, que atraiu os mais jovens para mobilizações em prol da mudança social e política.

O papel dos movimentos estudantis e das universidades nesse contexto foi essencial, uma vez que os estudantes representaram o núcleo duro da radicalização dos movimentos de 1968. Nos anos 1960, a população universitária cresceu significativamente e foi dentro dela que algumas contradições subjetivas relacionadas a valores morais predominantes passaram a ser contestadas. Na sociedade francesa, os movimentos universitários e secundaristas contestavam a aliança hegemônica do regime gaullista, sendo influenciada por pensadores como Focault e Althusser e suas concepções sobre poder, discurso e instituições sociais. Assim, o pensamento crítico se sobressaía entre os estudantes e a mudança social era reivindicada por estes (BIRHR, 2008). 0 movimento universitário se difundiu para o campo social e se uniu a outros movimentos de contestação - como o movimento sindical, trabalhador, feminista, etc. Em todos os países desenvolvidos já citados - EUA, México, França, Itália - a crise estrutural dentro das universidades precedeu os movimentos de protesto, e foi combustor para a contestação em outros campos. A partir do desenvolvimento de contestações em massa esses movimentos foram considerados como "Novos Movimentos Sociais" fazendo surgir o que os acadêmicos consideram como uma Nova Esquerda (BIHR, 2008).

Os movimentos de 1968 contestaram a ordem e o autoritarismo em todas suas formas. A Nova Esquerda surge para se distinguir da Antiga Esquerda reformista e social-democrata de partidos socialistas, e assinalar sua característica anti-capitalista e anti-comunista centralizadora. Essa Nova Esquerda acreditava que o socialismo deveria eliminar a alienação dos indivíduos, não apenas nos meios de produção, mas também na sua vida cotidiana, no âmbito familiar e nas relações sexuais e societárias. Para Katsiaficas (2018) as principais características dessa Nova Esquerda Global são: (1) a oposição à dominação racial, política e patriarcal, bem como a exploração econômica dessas camadas; (2) a criação de um conceito de liberdade, não só material, mas também de criar novos seres humanos nas sociedades (oposição à opressão psicológica e cultural); (3) a extensão da democracia e expansão de direitos individuais (conceito de participação das bases "bottom up"); (4) o aumento de bases da revolução (inserindo nesta, grupos considerados marginais como os estudantes, minorias nacionais, comunidade negra, lumpenproletariado, etc.); e, (5) a ênfase na ação direta, acreditando que o movimento se ampliaria e se tornaria mais forte, substituindo a noção predominante na Esquerda clássica de organização centralizada. 
Assim, as rebeliões constituíram-se como um movimento e não uma organização partidária ideológica e centralizada. Os protestos de 1968 buscaram preservar as relações horizontais, sem lideranças visíveis. Posto isto, a Nova Esquerda não detinha autoridade de nenhuma organização ou entidade superior e, portanto, buscava se difundir e crescer por meio de movimentos insurgentes por todo o mundo (KATSIAFICAS, 2018). Nesse sentido, o simbolismo evidente que o movimento de 1968 trazia, buscava acima de tudo, promover uma "contra-cultura" focando na centralidade ideológica de suas demandas, no comportamento e na vida cotidiana - a subjetividade do movimento se focava, portanto, em questões relacionadas à sexualidade, drogas, vestimentas e de contestação a formas culturais predominantes (HOLTEY, 2014).

É nesse contexto em que há uma forte mobilização social contra a Guerra do Vietnã impulsionada pelos Movimentos civis (sendo o festival em Woodstock um exemplo dessa mobilização) unindo vários protestos em prol do fim da invasão norte-americana no país. Ademais, 1968 foi o ano em que o Movimento Negro e o movimento feminista se tornaram notáveis e vários protestos foram mobilizados (KURLANSKY, 2005; HOLTEY, 2014).

Os protestos que se iniciaram na década de 1960 buscavam sua independência de partidos políticos e procuraram à auto-organização, a democracia direta além da solidariedade global em cadeia. Dito isso, é importante salientar que houve uma importante sincronização dos movimentos em todo o mundo - isso se tornou um elemento característico do poder de mobilização para a ação coletiva dos protestos a partir de 1968 (KATSIAFICAS, 2018). Assim, os movimentos de subversão propunham uma mudança não apenas no âmbito externo (instituições políticas, partidos, Estados), mas também uma transformação cognitiva, isto é, uma mudança nas percepções de mundo. A estratégia promovida por muitos movimentos que se influenciavam ao redor do mundo tomava forma de ação provocativa e de desobediência civil por meio da ocupação de espaços públicos e discursos - como os protestos sit-in nos Movimentos de Direitos Civis, nos Estados Unidos (HOLTEY, 201 4). Wallerstein e Zukin (1989, p.440) concluem que os resultados do movimento foram múltiplos, como afirmam: "One result is that the legal situations (state policies) have changed. A second result is that the situations within the antisystemic movements have changed. A third result is that mentalities have changed". Percebe-se assim, que a onda de protestos de 1968 trazia profundos impactos para as sociedades e nações ao redor do mundo, não apenas no que tange os fatores domésticos legais dos Estados nacionais, mas também na situação cognitiva e mental dos indivíduos, que buscavam posicionar-se contra uma estrutura sistêmica de valores e práticas conservadoras.

Diante disso, pode-se depreender que os protestos iniciados a partir do fim da década de 1960 tinham como objetivo a mudança das instituições políticas, das formas de poder e das ideias predominantes. Assim, a contestação do status quo é uma característica importante desses movimentos. O desenvolvimento de novos modos de produção, da tecnologia e meios de comunicação instantâneos, da difusão de ideias com princípios modernistas, racionalistas e 
democráticos foram essenciais para propulsionar o despertar das sociedades em prol de mudanças estruturais. A participação intensa de jovens secundaristas e universitários foi uma condição de escopo para o alastramento desses protestos em outros campos, como o sindicalista, o feminista, etc. Assim, a radicalização social percebida após 1968 deve ser entendida por um prisma muito mais amplo, a qual apelou para um posicionamento contestatório das relações culturais, políticas, sexuais e sociais predominantes.

Nas próximas páginas o foco do trabalho será convergido para o Movimento Negro e suas principais conquistas na sociedade norte-americana. O Movimento Negro de 19682 iniciado décadas antes por lideranças preeminentes, promoveu uma mudança de percepções e de normas institucionais na sociedade dos Estados Unidos. Foi uma ação coletiva e uma organização contestatória que buscava inserir o negro na realidade norte-americana e desafiar as estruturas racistas institucionalizadas pelo regime $\mathrm{Jim} \mathrm{Crow}^{3}$

\section{O MOVIMENTO NEGRO A PARTIR DE 1968}

O Movimento Negro nasce nos Estados Unidos em resposta à segregação institucionalizada do Regime Jim Crow ${ }^{2}$ durante os anos 50 no país. Após o período de escravidão, o regime Jim Crow foi a maneira encontrada pelo Estado para manter a população negra estadunidense sob dominação e subordinação. Nesse sentido, Morris (1999) assume que o modelo possuía um sistema de repressão social tripartite: politicamente (uma vez que os negros eram impedidos de participar do processo político no Sul do país); socialmente (visto que muitos direitos e acesso a bens públicos eram limitados a essa camada da população) e; economicamente (já que a população negra era restringida de deter o mínimo controle sobre a ordem econômica). Esse sistema impunha à população negra a segregação institucionalizada por meio da distinção entre uma sociedade branca e outra negra (afro-americana). Sendo assim, os termos do regime tendiam a designar os lugares sociais em que a população negra deveria ocupar e frequentar, como: escolas, banheiros, assentos de transportes públicos, igrejas, hotéis etc.

Nesse sentido, em termos de relações raciais étnicas, o Movimento dos Direitos Civis é uma das mobilizações mais proeminentes para se compreender a evolução do Movimento Negro durante as décadas de 1950-1970. Na realidade, o Movimento do Poder Negro tem sua difusão de princípios ideológicos após as conquistas que o Movimento dos Direitos Civis alcançou com protestos não

\footnotetext{
2 Emprega-se a expressão "Movimento de 1968" por se compreender, de modo geral, que a onda de protestos se tornou mais forte e difundido a partir do fim da década de 60. No entanto, o movimento global, bem como suas demandas sociais, políticas e econômicas não é estático. No caso do Movimento Negro norte-americano, as demandas por Direitos Civis se inicia em 1954 e tem seu ápice na radicalização em 1968.

${ }^{3}$ As leis Jim Crow foram leis locais e estaduais nos Estados Unidos que institucionalizaram a segregação baseada na cor dos indivíduos. As leis designavam instalações separadas para brancos e negros em vários espaços da sociedade estadunidense, entre 1876 e 1965.
} 
violentos liderados por figuras como Martin Luther King Jr, John e Robert F. Kennedy (JOSEPH, 2010).

Nota-se que o movimento em prol dos Direitos Civis nos Estados Unidos ocorreu entre 1954 e 1968, no entanto, protestos contrários ao sistema segregacionista já ocorriam desde o início do século XX, principalmente em regiões do Sul do país. Em 1909, por exemplo, foi fundada a National Association for the Advancement of Colored People (NAACP), primeira organização nacional contra as desigualdades do regime Jim Crow, tendo como principal figura William Edward Burghardt Du Bois. Em 1920, as ideias de supremacia branca e inferiorização da população negra foram desafiadas pelo movimento liderado por Marcus Garvey, tornando-se um dos maiores movimentos no país que enaltecia a população negra, cultura, história e raízes tradicionais africanas. Para Garvey, os afroamericanos deveriam retornar a África e suas ideias e princípios referentes ao nacionalismo negro foram difundidas para uma parcela da população afro-americana nos EUA (MORRIS, 1999).

A manutenção e aprofundamento do regime Jim Crow fez com que o movimento contra o sistema se despertasse no âmbito da população afro-americana e se tornasse mais acentuado na década de 1950. Em 1954, por exemplo, o caso Brown V. Board of Education of Topeka na Suprema Corte do país, considerou inconstitucional, as divisões raciais entre estudantes brancos e negros nas escolas públicas. No entanto, em 1955, Emmet Till, um garoto de 14 anos negro de Chicago, foi linchado até a morte no Mississipi por assobiar para uma garota branca. 0 crime demonstrou que, mesmo que normas legais buscassem impedir a manutenção do sistema de segregação, a população branca ainda utilizava de meios violentos para inferiorizar os afro-americanos. A exoneração dos réus pelo assassinato de Till foi divulgada por diversos meios de comunicação e despertou a atenção do público e, em especial, da comunidade afro-americana (ROBINSON, 2012).

Nesse contexto, o ano de 1955 foi marcado por protestos em massa da população negra nos EUA e foi também o ano que marcou o boicote aos transportes públicos em Montgomery, Alabama. Isso ocorreu quando Rosa Parks, uma ativista do NAACP, se recusou a conceder seu assento para um homem branco e seu posicionamento influenciou uma onda de boicotes aos transportes públicos, os quais foram capazes de demonstrar o poder de mobilização da comunidade negra contra o sistema de segregação institucional no país.

Nessa onda de reivindicações e boicotes durante os anos 1950, salienta-se que a igreja teve um papel essencial na mobilização dos protestos pacíficos. Esse contexto foi marcado pela criação da Montgomery Improvement Association (MIA), primeiro movimento social com grande visibilidade voltado para protestos de ação direta da população negra. Martin Luther King Jr. é uma figura chave nessa configuração quando, em 1957, foi eleito presidente da Southern Christian Leadership Conference (SCLC), uma organização que buscava a promoção dos direitos civis nos EUA, tendo como foco a junção de movimentos estudantis, da igreja e outros movimentos não violentos no país. Assim, foi por meio da ação não violenta, a qual resgatava os princípios de resistência e conquistas 
do movimento Ghandiano, que a SCLC foi capaz de mobilizar uma grande camada da população em prol do fim do regime de segregação no país. 0 sucesso percebido em Estados do Norte disseminou a atuação nas regiões do Sul do país, onde a segregação era mais intensa. A comunidade negra e parte da população branca se juntavam na luta por direitos civis aos afros americanos (MORRIS, 1999; ROBINSON, 2012).

Salienta-se que o Movimento por Direitos Civis nos EUA deve seu sucesso à forte presença de estudantes e protestos em universidades renomadas no país. O Student Non- violent Coordinating Committee (SNCC) é uma importante organização nesse contexto, justamente por ser formada por jovens estudantes que se mobilizaram e protestavam no sul do país no início da década de 1960. Nesse sentido, o SNCC ganhou reconhecimento na luta pelos direitos civis da população afroamericana por seus esforços em organizar o registro de eleitores, as Freedom Schools e outros programas comunitários (ROBINSON, 2012; MORRIS, 1999; RISSMAN, 2015). O papel proeminente de estudantes universitários foi essencial para articular as demandas do movimento nas instituições de ensino superior e organizar a mobilização por meio dos sit-ins ${ }^{4}$.

Em 1960 os sit-ins em Greensboro foram eventos significativos que despertaram a atuação em cadeia de afro-americanos em prol de direitos civis frente ao regime segregacionista. Ao se sentarem em assentos designados para brancos na loja de Departamento Woolworth, os Greensboro Four - Ezell Blair Jr., Franklin McCain, Joseph McNeil e David Richmond -, estudantes da universidade da Carolina do Norte, desafiaram o sistema segregacionista e resistiram à opressão exercida no sul do país. Assim, as manifestações a partir desse evento passaram a ser mais recorrentes e a prática de sit-ins se disseminou por todo país nos meses seguintes devido a divulgação da mídia. Em poucos dias as demonstrações tomaram muitas cidades da Carolina do Norte, em Nashville, Tenessee e Nova Iorque e, nos meses seguintes, mais de cinquenta mil práticas de sit-ins foram exercidas pela comunidade afro-americana nas cidades do sul do país (BILYEU, s.d).

Outros acontecimentos foram substanciais para a promoção do fim do regime Jim Crow, pelo menos a nível institucional, estes foram: o movimento de Birmingham, no Alabama e em Selma, em 1963 e 1965, os quais geraram fortes protestos entre a população dos Estados Unidos e utilizaram a ação coletiva não violenta visando desestabilizar a ordem social. Ao pressionar o governo Federal, esses atos de protesto do Movimento Negro, forçaram o governo a promover mudanças. Em 1964, o presidente Johnson aprovou o Civil Rights Act, um marco legal que derrubou formalmente o regime segregacionista instituído pelo sistema Jim Crow (MORRIS, 1999). Nesse sentido, a sanção da lei dos direitos civis foi essencial para proibir, a nível legal, qualquer tipo de discriminação baseada na raça, religião, origem nacional e sexo.

Outros movimentos foram capazes de se beneficiar com as conquistas do Movimento pelos

\footnotetext{
${ }^{4} 0$ sit-in ou sit-down (protestos sentados) é uma tática de ação coletiva direta que envolve uma ou mais pessoas ocupando uma área para protestar. As pessoas ocupam espaços sentando-se neles, promovendo uma ação direta não-violenta.
} 
direitos civis, encabeçada pelos afro-americanos, como o movimento feminista, o qual buscava maior representação no Congresso e na sociedade em geral. A tática de protesto utilizada pelo Movimento pelos Direitos Civis (boicote econômico, sit-ins, marchas, etc.) influenciou a atuação de outros movimentos sociais ao redor do mundo. 0 movimento para os direitos civis mostrou o poder que a mobilização e ação coletiva têm ao modificar estruturas de segregação institucionalmente estabelecidas na sociedade norte-americana. Ao se disporem, por meio da ação não violenta, serem encarcerados, espancados, e até mesmo mortos pela causa, eles obtiveram um importante papel ao encorajar outros movimentos a confrontar as autoridades centrais em prol de mudanças sociais (MORRIS, 1999).

O movimento Black Power pode ser compreendido como um debate histórico que se inicia, para a maioria da literatura, a partir de 1965 e tem seu ápice no fim dos anos 1960. Muitos autores assumem que o Black Power é um movimento de continuidade em relação ao Movimento dos Direitos Civis precedente. Nesse sentido, Robinson (2012) afirma que o Black Power e o Civil Rights Movements são movimentos que se complementam e compõem partes diferentes de uma mesma causa. Joseph (2010) acrescenta esse argumento salientando que é no inicio dos anos 1960, com a popularização de Malcolm X e seu contraponto à ação pacífica e não violenta de Martin Luther King Jr., que o movimento passa a tomar força. Nesse sentido, para o autor, o Movimento dos Direitos Civis e o Poder Negro não são mutuamente exclusivos, mas paralelos e interseccionados.

O movimento Black Power foi marcado por uma forte radicalização e contestação direta das estruturas segregacionistas, marcando um renascimento artístico, cultural, ideológico e político da cultura afro-americana. Para Johnson (2007) o período:

(...) was characterized by a vibrant black public sphere composed of a diverse array of bookstores; alternative magazines and underground newspapers; radio and television programs; small local publishing houses; and scores of political organizations, independent schools, study groups, and university-based black/Africana studies departments and research centers. Many activists rallied around the ideal of indigenous control-the seizure of those institutions and resources within black communities. Still, the Black Power movement contained much ideological and regional variation. (op. cit, p. 22)

Entre 1954 e 1965 as proposições ideológicas de Malcolm X já possuíam força em cidades como Nova York e regiões próximas. Nesse sentido, o movimento buscava o orgulho racial e cultural do povo negro, buscando uma política de autodeterminação por meio de protestos provocativos. 0 Black Power se alinhava com demandas em prol da justiça racial e lutas anticoloniais no Terceiro Mundo, desafiando dessa forma, a ordem bipolar da Guerra Fria (JOSEPH, 2010).

Nesse sentido, Johnson (2007) enfatiza que o Black Power era composto por ativistas radicais, os quais - contrários a práticas da não violência manifestada nos movimentos anteriores para os direitos civis por não verem mudanças ocorrendo na sociedade - aclamavam a rejeição e confrontação de padrões estéticos ocidentais, a solidariedade das populações oprimidas no Terceiro 
Mundo e um direcionamento anticapitalista. Assim, o período foi marcado pela ascenção de várias organizações nacionalistas como a Black Arts Repertory Theater/School, US Organization, Committee for a Unified Newark, Student Organization of Black Unity, Black Student Union, Black Panther Party for Self Defence (BPP), entre outros.

A origem do movimento do Black Power pode ser datada a partir de 1964 após a sanção do Civil Rights Act. Apesar de ter sido um importante marco legal para o fim da segregação na sociedade norte-americana, a lei não impediu, empiricamente, que atos de preconceito fossem praticados por autoridades e pela comunidade branca racista. Nesse sentido, Katsiaficas (2018) salienta que entre 1964 e 1969 as mais de 239 confrontações violentas entre afro-americanos e forças policiais em cidades afro-americanas mataram, pelo menos, 191 pessoas e deixaram mais de oito mil feridos. Esse momento foi marcado por um novo alento no Movimento Negro nos Estados Unidos, o qual propunha a revolução para a solução dos problemas não só sociais internos, mas também na comunidade internacional.

Um importante marco para a nova orientação do Movimento Negro por direitos civis para a ação disruptiva do movimento Black Power é a mudança de trajetória do SNCC em 1965, momento em que a organização abandona o pacifismo e abraça os princípios e bases ideológicas confrontadoras do Black Power. O programa para a autonomia do poder negro encabeçado pelo SNCC buscava expulsar a presença de membros brancos e insistir que estes deveriam lutar contra o racismo em suas próprias comunidades, ao invés de assumir posições paternalistas com relação à luta dos afro-americanos. Ademais, o SNCC advogava por posições reacionárias e contra conflitos internacionais engajados pelos EUA - como a guerra no Vietnam, em que os membros afroamericanos eram tratados de forma desigual (RISSMAN, 2015; ROBINSON, 2012).

Em 1966, James Meredith promoveu a Marcha Contra o Medo em que planejava percorrer de bicicleta a rota de Memphis, no Tennesse, até a cidade de Jackson, no Mississipi. No segundo dia de Marcha, todavia, o ativista levou um tiro em uma emboscada. Esse ato racista provocou uma ação em cadeia por parte dos ativistas - desde os moderados como a base clériga da SCLC até a mais militante, como membros do Congress of Racial Equality (CORE) e o SNCC a protestos conjuntos. Em Greenwood, um membro ativista do SNCC, Stokely Carmicheal foi preso por protestar contra a polícia, a qual proibia que os ativistas montassem tendas no chão das escolas. Ao ser dispensado, o militante fez um discurso a um público de seis mil pessoas em que afirmava: "[t]his is the twentyseventh time I have been arrested. I ain't going to jail no more [w] hat we gonna start saying now is 'Black Power'”' (CARMICHAEL, 1966). Com essa frase, o ativista resumiu as frustrações da maioria da população afro-americana, e o termo Black Power difundiu-se por toda sociedade e reorientou o debate público sobre a segregação e tratamento desigual a população afro-americana nos Estados Unidos (JOHNSON, 2007). Para Joseph (2010) o discurso de Carmichael foi o ponto de partida para a transição do movimento no cenário político estadunidense. Após a morte de Malcolm X, Stokely 
Carmicheal tornou-se o líder do SNCC e foi um dos porta-vozes do Movimento Negro radical.

Robinson (2012) define o Black Power como um movimento com vários ideais e objetivos. Os mais fundamentais incluem o orgulho negro e a autodeterminação. 0 maior impulso do Black Power era o nacionalismo negro, o qual buscava a consciência negra na comunidade afro-americana e o empoderamento por meio da independência de instituições e pessoas brancas. 0 movimento também militava pela autodefesa ou violência retaliatória, pelo apoio a consciência negra (orgulho da raça) e solidariedade negra e pelo apoio ao aumento de poder dos negros para a demanda por políticas públicas em prol da comunidade. Apesar de pontos em comum, o movimento também se distinguia internamente entre as ideologias de assimilação, de pluralismo e de nacionalismo negro.

O Black Panther Party (BPP) é talvez o movimento mais conhecido portador dos princípios ideológicos do Black Power como forma de luta e resistência da população negra e suas raízes culturais. Fundado por Bobby Seale e Huey Newton em 1966, em Oakland, Califórnia, o partido dos Panteras possuíam uma agenda de autodefesa, patrulhando as autoridades oficiais e andando armados (protegidos pela legislação da Califórnia) para garantir o fim da brutalização de afroamericanos por meio de forças policiais (JOHNSON, 2007). Depois de menos de dois anos de sua formação, o Partido havia crescido substancialmente na sociedade estadunidense. Após o assassinato de Martin Luther Jr., suas pautas tornaram-se ainda mais incorporadas pelos afroamericanos.

Em 1968, o partido recrutou 800 mil pessoas na Cidade de Nova York. Muitos candidatos do Pantera Negra conseguiram se eleger para cargos públicos e, em 1969, eles tinham filiais em 45 cidades do país. Os militantes do BPP tiveram importante atuação a nível regional nas comunidades estadunidenses ao endossar o Movimento Black Power com programas sociais em cidades grandes, subúrbios, áreas rurais e cidades universitárias. Assim, os membros do partido eram responsáveis por clínicas médicas, campanhas contra anemia falciforme, transportes públicos para auxiliar as famílias a visitar seus familiares nas prisões, programas de agasalho, cafés gratuitos para crianças que alimentava dezenas de jovens, entre outros (JOSEPH, 2010; JOHNSON, 2007). Organizado como um partido Marxista-Leninista, o Black Panther estava sob a autoridade de um comitê central, em Oakland, e, dentro de cada filial, existia uma hierarquia estrita.

Pela orientação política do partido dos Panteras e sua ação diretamente confrontadora com as autoridades e governo norte-americano, em 1969, o diretor do FBI, Edgar Hoover, considerou os Panteras como a maior ameaça à segurança interna dos Estados Unidos. Nesse sentido, a polícia passou a desenvolver estratégias a fim de enfraquecer o partido. A COINTELPRO (Programa de Contra inteligência do FBI) organizou uma operação completa em base nacional e, em 1968 os escritórios dos Panteras foram atacados em todo país. Em 1970, devido a intensa atuação do Programa do FBI, a maioria dos membros do Comitê Central do BPP haviam sido mortos, presos ou forçados ao exílio, são eles: Huey Newton, Eldrigde Cleaver, Kathleen Cleaver, Bobby Seales, Ericka 
Huggind e Fred Hampton (MORRIS, 1999).

Assim, apesar de continuar com crescimento substancial, o BPP passou a ser atacado de forma impetuosa pelas forças do governo dos Estados Unidos e, consequentemente, passou a se enfraquecer no fim da década de 1960. 0 intuito da COINTELPRO era de colocar os membros do movimento Black Power uns contra os outros. 0 FBI admitiu posteriormente que, durante a atuação da COINTELPRO (1956-1971), as operações eram orientadas diretamente a organizações e indivíduos ligados ao movimento de libertação negra, em especial ao Partido Pantera Negra entre 1967-71 (RISSMAN, 2015). Essa repressão por parte do aparato estatal estadunidense causou o colapso do Partido em 1971. Alguns membros seguiram em movimentos do Black Power como o Black Liberation Army, mas a organização fundada em Oakland pelo nome de Black Panther Party não era mais uma força política na sociedade norte-americana nos anos 1970 (CHURCHILL, WALL, 2002).

Os anos de 1966 a 1970 marcam o período clássico do movimento do Black Power principalmente no que tange sua popularidade entre a população afro-americana. Após o fim do partido dos Panteras Negra e um enfraquecimento substancial das mobilizações e práticas disruptivas após 1970 pode-se afirmar que ambos momentos de mobilização (Civil Rights Movement e Black Power) foram essenciais para uma mobilização social nacional e internacional em prol de mudanças nas estruturas sociais e institucionais de todo globo. Como parte do Movimento de 1968, as conquistas do Movimento Negro foram modelo para muitos países no que tange a demanda de direitos sociais e mudança de perspectiva sobre seus lugares dentro da sociedade. Nesse período, a prevalência de solidariedade e a crença no processo revolucionário eram características marcantes. A ascensão de novas organizações e a transformação das universidades como um espaço de contestação em resposta às demandas de negros, latinos, asiáticos e mulheres foram importantes para chamar a atenção a pautas específicas e criação de programas. 0 Movimento Negro nos Estados Unidos entre 1954 e 1971, conectou-se com os processos de descolonização na África e Ásia e processos revolucionários na América Latina.

Para Morris (1999), a evolução de ferramentas tecnológicas - satélites de comunicação - foi um advento essencial durante o período de revoluções de 1960, tornando-se essenciais na difusão das ações coletivas e divulgar, através da mídia, a luta e reivindicações do Movimento Negro a milhões de pessoas na arena internacional. A influência do movimento social dos afro-americanos sentiu sua repercussão ao redor do mundo, de modo que protestos não violentos ocorreram na África do Sul, no Oriente Médio, nas demonstrações pró-democracia na China. Ademais, o movimento se tornou uma ferramenta para a agitação no Terceiro Mundo, ações não violentas se difundiram durante 1960-70, como: na Primavera de Praga, no movimento de estudantes de 1968 pelos movimentos de paz ambiental na Europa e America, pelos oponentes do regime nas Filipinas e contra o regime militar na Tailândia e Burma. No Brasil, esse Movimento chega ao final na década de 
1970 e, apesar predominante discurso da democracia racial, a sociedade brasileira passou a aderir muitos princípios e valores do movimento Black Power norte-americano. Salienta-se que estes foram essenciais para uma mudança de paradigma que, embora tardia - ocorrida apenas na década de 90 demonstra o histórico de lutas e reivindicações da população negra por melhores condições sociais, políticas e econômicas.

Pode-se assumir o Movimento Negro nos Estados Unidos como um despertar da comunidade afrodescendente no que tange a décadas de alteridade e segregação de direitos civis a essa população. A relevância desses protestos para a presente análise se dá na profunda difusão das táticas disruptivas e, principalmente, nas conquistas promovidas por meio de uma ação coletiva que, em um primeiro momento demandava seus direitos por meio da prática não violenta (boicotes, sitins, protestos em geral) e, posteriormente, passa a insurgência mais confrontadora às instituições predominantes de segregação na sociedade. A reafirmação da negritude no contexto estadunidense é essencial para se compreender uma transformação cognitiva de negros e negras na sociedade, bem como o resgate a raízes culturais africanas (cabelo, músicas, vestimentas). 0 Black Power configurase assim, como um movimento que busca romper com as antigas estruturas de dominação branca e, não só clamar, mas também reivindicar direitos para esta população.

\section{O MOVIMENTO NEGRO NO BRASIL}

O Movimento Negro no Brasil foi importante agente que fomentou a ação coletiva em prol de mudanças na sociedade brasileira no que tange o racismo e a segregação de negros nos diversos espaços da sociedade. Muitos autores afirmam que o Movimento Negro busca lutar contra a democracia racial a qual, de acordo com Abdias Nascimento (1978), é a falsa assunção de que as condições de oportunidades entre brancos e negros na sociedade brasileira existem de forma harmoniosa, pregando, assim, a inexistência de raças ou etnias na sociedade brasileira e, em contrapartida, a unicidade de apenas uma identidade: a brasileira. De acordo com o autor, os mitos existem para esconder a realidade e, o da democracia racial, existiu para estabelecer a indiferença quanto ao sistema escravocrata e para expressar um meio de evasão das camadas dominantes frente as responsabilidades intransferíveis da escravidão.

0 conceito de democracia racial enraizou-se na sociedade brasileira para se diferenciar de países que promoveram a institucionalização da segregação, como apresentado anteriormente no exemplo norte-americano com o regime Jim Crow ${ }^{5}$. Assim, para Hanchard (1994) as elites dirigentes brasileiras buscaram difundir a noção de que o país havia superado questões raciais em função da questão nacional. 0 discurso de excepcionalismo racial, nesse sentido, não se atenta às reais

\footnotetext{
${ }^{5}$ África do Sul, com o regime do Apartheid, pode ser outro exemplo.
} 
estruturas de segregação baseadas na cor e, mais importante, tem sua legitimação entre camadas sociais, no senso comum e na discussão entre elites intelectuais e políticas. Ao não se relacionar diretamente com regimes de segregação institucionalizadas como a estadunidense, as estruturas racistas existentes foram mascaradas na sociedade brasileira.

Um marco histórico para a instauração da democracia racial foi a assinatura de um decreto, por Rui Barbosa, para a incineração de toda documentação relativa ao regime escravocrata no Brasil após a abolição (registros estatísticos, demográficos, financeiros, dentre outros). Assim, todos os registros relativos à escravidão ao tráfico negreiro e aos escravizados desapareceram fisicamente da história do Brasil. Para Ribeiro (2013) e Nascimento (1978) isso significou a tentativa do Estado de apagar a memória histórica do regime escravocrata. Ao queimar os documentos, os donos do poder entendiam que também estavam abolindo os fatos históricos da escravidão e, em consequência disso, não existe hoje uma compreensão lógica sobre a experiência africana e de seus descendentes no país. Esse evento marcou o primeiro intento de um sistema que, posteriormente, se estruturou na sociedade brasileira de justiça social e igualdade democrática. Abdias Nascimento (1978) assume que se manteve, com a democracia racial, um complexo de privilégios, padrões de comportamento e valores de uma ordem social arcaica em detrimento da raça branca. Em teoria, no Brasil não importaria a cor da pele nem a descendência dos indivíduos, visto que todos eram resguardados sobre uma identidade nacional; na prática, a classe dominante branca sempre buscou construir uma democracia artificial controlando os meios educacionais, políticos e econômicosociais. Sendo assim, o mito da democracia racial floresceu sem contestações até que os próprios negros passaram a compreender suas condições sociais e econômicas e manifestar seu protesto contra as estruturas de poder dominantes.

Domingues (2007) define o Movimento Negro como a luta dos negros na busca da resolução dos problemas na sociedade, principalmente àquelas questões que se desenvolvem devido o preconceito e a discriminação racial. Assim, as estruturas que marginalizam os negros no mercado de trabalho, no sistema educacional, político e também social são contestadas dentro desse movimento. Ribeiro (2013) advoga no mesmo sentido, afirmando que o Movimento Negro é um porta-voz das proposições e reivindicações da população negra buscando a redistribuição e reconhecimento desta.

Embora o foco do presente trabalho seja na reivindicação do Movimento Negro no Brasil após as revoluções de 1968, é importante salientar que as manifestações desses protestos datam de décadas anteriores. Como o Movimento Negro nos Estados Unidos, a mobilização do Movimento no Brasil contemporâneo e suas conquistas são entendidas por acadêmicos como uma continuidade das lutas travadas no passado (RIBEIRO, 2013). 0 quilombo, por exemplo, se tornou o significado de resistência negra e, com a evolução do Movimento Negro, se tornou um símbolo de luta por direitos. Nesse sentido, Ribeiro (2013,) afirma: 
Em geral, ao se tratar da referência histórica das lutas contra a escravidão destacamse os quilombos, e, entre eles, o Quilombo de Palmares, como o mais importante e continuado foco de resistência no período da escravidão. Essa frente de luta sofreu permanentes ataques, resultando em um deles no assassinato de Zumbi dos Palmares, em 1695 (op cit, p. 82).

Ao atentar-se para a organização da comunidade negra na sociedade brasileira, percebe-se que logo após a abolição, os ex-escravizados e seus descentes passaram a se organizar em movimentos de mobilização racial em resposta a forte marginalização da sociedade brasileira a população negra. No início do século XX nascia um conjunto de clubes, grêmios e associações do movimento de "Homens de Cor". Em São Paulo, por exemplo, foi criado o Clube 13 de Maio dos Homens Pretos, em 1902; o Centro Literário dos Homens de Cor, em 1903; a Sociedade União Cívica dos Homens de Cor, 1915, entre outras ${ }^{6}$ (DOMINGUES, 2006). Nesse mesmo período, passa a se organizar a chamada Imprensa de Negros, feita para e pelos negros, a qual buscava auxiliar na autoafirmação de negros libertos e se focar em questões que afetavam a população nas áreas da educação, saúde, trabalho e habitação. Alguns jornais importantes podem ser citados, como: o Menelick (1915), A Rua e o Xauter (1916), o Alfinete (1918), O Bandeirante e a Liberdade (1919), o Clarim Alvorada (1924), entre outros. Esses jornais tinham o papel crucial de denunciar o regime de segregação racial no Brasil, que impedia a entrada de negros em diversos espaços públicos, como hotéis, clubes, cinemas, teatros etc. (RIBEIRO, 2013; DOMINGUES, 2007).

Em 1931 se percebe um salto no Movimento Negro com a fundação, em São Paulo, da Frente Negra Brasileira (FNB), a qual, juntamente o Centro Cívico de Palmares, foi considerada a primeira organização de negros com reivindicações políticas deliberadas (DOMINGUES, 2006). A FNB promoveu um dos primeiros protestos de âmbito nacional, o qual foi capaz de mobilizar a população negra e difundir-se por todo país. Durante a primeira metade do século XX, a FBN foi a principal entidade negra do país e transformou-se em partido político em 1936, buscando a representação da "população de cor" nos espaços políticos. No entanto, com a instauração do Estado Novo, em 1937, a FBN é extinta juntamente a todos os outros partidos existentes naquela época. Para Nascimento (1978) os movimentos que se organizaram nesse período, buscavam denunciar a ordem legal vigente e sua ineficácia na promoção de políticas que valorizassem os negros na sociedade brasileira. Apesar de grande ressonância nacional, os movimentos desse período se limitaram a minorias ativistas. Nesse sentido, se inaugurou, até o início do Estado Novo, uma incipiente ruptura racial. A ditadura getulista, no entanto, faz o movimento hibernar e, de certo modo, restaurou e recompôs a capacidade de dominação oligárquica das classes dominantes.

Em 1944, surgiu o Teatro Experimental do Negro (TEN), organizado por Abdias do

\footnotetext{
${ }^{6}$ A fundação de clubes e associações em outros Estados do País também ocorre, como: a Associação Protetora dos Brasileiros Pretos(1917); no Rio de Janeiro, o Centro da Federação dos Homens de Cor; em Pelotas/ RG, a Sociedade Progresso da Raça Africana (1891); em Lages/SC, o Centro Cívico Cruz e Souza (1918) (DOMINGUES, 2007).
} 
Nascimento. O TEN propunha o resgate de valores da cultura africana por meio da valorização do negro no Brasil por meio da arte e cultura. Junto ao grupo União dos Homens de Cor (UHC)7 , o TEN foi um grupo essencial para a mobilização do Movimento Negro até o início da ditadura militar. É importante enfatizar que o grupo não se limitava apenas a manifestações artísticas em prol do Movimento Negro, mas teve também uma atuação mais ampla ao publicar o jornal "O Quilombo"; ao oferecer cursos de alfabetização, corte e costura; ao fundar o Instituto Nacional do Negro; e Fundar o Museu do Negro e organizar o I Congresso do Negro Brasileiro. No âmbito político, o TEN advogava pela criação de uma legislação antidiscriminatória no Brasil. Assim, o grupo foi pioneiro ao adotar o movimento da negritude francesa na sociedade brasileira. Todavia, com a instauração da ditadura militar, em 1964, o grupo enfraqueceu, principalmente quando o seu principal dirigente, Abdias Nascimento, partiu para o autoexílio em 1968 (RIBEIRO, 2013; DOMINGUES, 2007).

Domingues (2006) salienta que o golpe militar de 1964 representou uma derrota temporária para a luta do Movimento Negro, uma vez que desarticulou uma mobilização em crescimento. A reorganização do movimento ocorre apenas no final da década de 1970, devido a abertura política da ditadura e da ascensão de vários movimentos contestatórios em prol da democracia - como o movimento estudantil, sindical, popular, etc. Nesse sentido, para Ribeiro (2013), a tarefa do Movimento Negro em 1970 foi de desafiar o mito da democracia racial e atacar essa construção mantida pela elite brasileira por décadas.

Ainda em 1972, um grupo de estudantes formou o Centro de Cultura e Arte Negra (CECAN), em São Paulo, e a Imprensa Negra retorna sua atuação de forma acanhada com os jornais Árvores da Palavra (1974), e o Quadro (1974). Em Porto Alegre, é fundado, em 1971, o Grupo dos Palmares, o primeiro no país que passou a defender a substituição das comemorações de 13 de maio (da abolição da escravatura) para 20 de novembro (morte de Zumbi dos Palmares) (PEREIRA, 2010; RIBEIRO, 2013). A mudança de datas demonstra um evidente posicionamento de confrontação das estruturas dominantes no Brasil. Muitos militantes do Movimento Negro não entendiam o motivo de se comemorar o fim da escravidão, já que um sistema racista e discriminatório ainda era presente na sociedade - para muitos era necessária uma segunda Abolição (NASCIMENTO, 1978). A data da morte de Zumbi é também expressiva, pois demonstra a comemoração da resistência de estruturas segregacionistas.

O Movimento Negro, a partir da metade da década de 1970, é fortemente influenciado pelo movimento Black Power dos Estados Unidos. Figuras como Martin Luther King Jr., Malcolm X e os Black Panthers inspiraram a atuação de muitos grupos do Movimento Negro no Brasil. O slogan "Black Power" foi traduzido de várias formas durante a década de 1970, e, em geral, influenciou de

\footnotetext{
${ }^{7}$ Fundada em Porto Alegre, em 1943, a entidade buscava elevar o nível econômico e intelectual dos negros em todo Brasil. Na década de 40, a UHC possuía representantes em, pelo menos, 10 estados brasileiros. Sua atuação foi marcada pela promoção de debates na imprensa, publicação de jornais próprios, serviços de assistência jurídica e médica, aulas de alfabetização, ações de voluntariado, etc. (DOMINGUES, 2007).
} 
forma crescente a forma como os negros brasileiros compreendiam sua cultura. Esse slogan foi essencial para gerar um sentimento de orgulho e união da comunidade negra no país. Além do Black Power, o movimento Soul - gênero musical norte-americano que trazia afirmações da negritude, como "Black is Beautiful" - penetrava na sociedade brasileira e difundia-se entre as comunidades afro- descentes brasileiras. No Rio de Janeiro, por exemplo, a juventude negra foi influenciada pelo Soul, batizado posteriormente de Black Rio. Nesse período, portanto, a comunidade negra no Brasil era convidada a ter uma atitude propositiva e de resistência quanto a questões culturais, sociais e políticas (DOMINGUES, 2007; PEREIRA, 2010).

Pode-se notar que, desde 1920, o Movimento Negro brasileiro e o norte-americano estavam em constante articulação. Em um primeiro momento, nota-se o constante diálogo entre a Imprensa Negra dos dois países (PEREIRA, 2010). Em 1988, Carmichael, uma das lideranças mais importantes do SNCC, visitou a Serra da Barriga em Alagoas para conhecer o Quilombo dos Palmares. Ademais, havia um intenso diálogo entre intelectuais e ativistas negros no Brasil e Estados Unidos, de modo que se criaram pontes para construir o diálogo coletivo, como no final da década de 1970, quando Anani Dzidzienyo convidou algumas lideranças do Movimento, como Abdias Nascimento, Carlos Alberto Medeiros e Lélia Gonzalez para dar palestras nos Estados Unidos sobre as relações raciais e o Movimento Negro no Brasil (PEREIRA, 2010).

0 movimento estudantil foi um espectro importante para essa nova fase do Movimento Negro na década de 1970. A presença de estudantes universitários no Movimento deveu-se, em grande parte, pelas estruturas segregacionistas impostas a esses jovens, mesmo após preencher alguns espaços que lhes eram historicamente negados. Para Abdias Nascimento (1978) a adesão de estudantes ao Movimento Negro se deve a sua configuração como "novo negro" dentro da sociedade brasileira. Esse grupo de estudantes chega às universidades por pertencer a uma "classe média de cor" incipiente nos anos 60 e 70. No entanto, a inserção de negros em um "mundo branco" gerou custos raciais, psicológicos e conflitos humanos. Esses jovens ficaram desorientados com sua posição no mundo dos brancos e manifestavam essas insatisfações nos jornais das universidades. Fortemente influenciados pelos movimentos irrompidos no mundo pós-1968 na Europa e Estados Unidos, esses jovens passaram a ver a raça como o eixo de um racismo institucional na sociedade brasileira e contestaram essas estruturas. Em 1978, ocorreu a Semana de Cultura Afro-Brasileira na Universidade de São Paulo (USP) reunindo diversos pesquisadores do país e desafiando as estruturas de segregação em uma das universidades mais tradicionais do país (RIBEIRO, 2013; DOMINGUES, 2005).

Em junho de 1978, diversos grupos do Movimento Negro (CECAN, Grupo Afro- Latino América, Câmara do Comércio Afro Brasileiro, Jornal Abertura, Jornal Capoeira etc.) reuniram-se e fundaram o Movimento Unificado Contra a Discriminação Racial (MUCDR). Em sete de julho, o 
MUCDR promoveu um ato unificado nas escadarias do Teatro Municipal de São Paulo contra a morte de Robson Silveira da Luz, torturado até a morte no $44^{\circ}$ distrito de Guaianases. Cerca de duas mil pessoas se reuniram no protesto e, nesse contexto o MUCDR configurava-se como o maior avanço realizado pelo Movimento Negro contra o racismo no Brasil (DOMINGUES, 2007). O MUCDR (que, posteriormente, torna-se apenas MNU (Movimento Negro Unificado), foi um marco na história do protesto do Movimento Negro no Brasil. Ao propor a unificação da luta com 101 organizações a nível nacional, a organização contestava a ordem social vigente, com um discurso político socialista e com suas principais lideranças ligadas a organizações radicais de esquerda, como a Convergência Socialista. O compromisso assumido entre PDT e lideranças como Leonel Brizola e Abdias Nascimento surgiram a fim de levar discussões sobre a questão racial ao Congresso Nacional (RIBEIRO, 2013; PEREIRA, 2010; DOMINGUES, 2005).

Em 1986, ocorreu a Convenção nacional "O Negro na Constituinte”, a qual se tornou um importante acontecimento para todas as entidades do Movimento em que se levantaram propostas de leis para se considerar o racismo como crime e o resguardo das terras do Quilombo. A constituição de 1988 acata essas demandas e reconhece, em seu artigo 88, sobre a propriedade definitiva das terras dos quilombos (PEREIRA, 2010). No mesmo sentido, o Artigo 5o da Constituição de 1988 criminalizou o racismo como delito inafiançável e imprescritível. Além dessas conquistas, no centenário da Abolição, o Movimento Negro ganha articulação com os poderes públicos de modo que se criou a Fundação Cultural dos Palmares, vinculada ao Ministério da Cultura, com o objetivo de promover a preservação dos valores culturais da influência negra na sociedade. Apesar de status apenas consultivo, o órgão tornou-se um grande passo para a concretização de demandas do Movimento Negro no Brasil. Essas conquistas qualificam o ano de 1988 como um dos mais importantes para o Movimento Negro no Brasil (RIBEIRO, 2013). 0 centenário da Abolição também abriu espaço para criação de novas Organizações Não Governamentais negras por todo Brasil, como Geledés (1988), em São Paulo, e o CEAP (1989), no Rio de Janeiro.

A Marcha Zumbi dos Palmares contra o Racismo, ocorrida em 1995 foi essencial para a mudança de posicionamento do Estado brasileiro quanto à questão Racial. Reunindo mais de 30 mil ativistas do Movimento Negro, mulheres negras, sindicatos e comunidades negras rurais, os manifestantes entregaram um documento ao então presidente, Fernando Henrique Cardoso, com as demandas para a promoção de políticas que visassem incluir os negros em vários setores da sociedade. Isso levou o governo federal a criar um Grupo de Trabalho Interministerial para a valorização da população negra (GTI) no mesmo ano e a reconhecer, em discurso oficial, a existência de estruturas racistas na sociedade brasileira ${ }^{8}$ (PEREIRA, 2010).

\footnotetext{
8 Esse discurso foi proferido por FHC, em 1995, no Seminário "Multiculturalismo e Racismo: o papel da ação afirmativa nos estados democráticos contemporâneo". Mais detalhes no link: <http://www.biblioteca.presidencia.gov.br/presidencia/expresidentes/fernando-henrique-cardoso/discursos/10- mandato/1996-1/02.pdf/view>.
} 
Apesar de acolher as demandas e reconhecer sua legitimidade no plano simbólico, o governo de Fernando Henrique não concretiza as iniciativas propostas, capazes de incluir a população negra no ensino superior e não promove políticas públicas que, de fato, mudassem esse cenário. De acordo com Santos (2011) e Ribeiro (2013) as iniciativas para as políticas públicas afirmativas ficaram a cargo de alguns parlamentares negros de partidos de esquerda como Benedita da Silva (PT/RJ), Paulo Paim (PT/RS), Luiz Alberto (PT/BA), Vicentinho (PT/SP), Carlos Santana (PT/RJ), Janete Pietá (PT/SP) e Evandro Milhomem (PCdoB/AP) articulados com movimentos sociais negros e em cargo de apresentar propostas de políticas públicas de ações afirmativas. No contexto partidário parlamentar, Ribeiro (2013) afirma que existem três principais categorias de agentes políticos que buscam se articular com organizações populares e contribuir para a formação de um movimento mais abrangente: movimento sindical, por meio da Central Única dos Trabalhadores (CUT), partidos políticos de esquerda, como o PT, e aqueles que realizam um trabalho de mediação junto aos movimentos populares. 0 Programa de Superação do Racismo e da Desigualdade Racial (publicado em 21/11/95), produto da Marcha dos Zumbis foi apoiado, por exemplo, pela CUT, pelo Partido dos Trabalhadores (PT), pela Central de Movimentos Populares (CMP), pelo Movimento dos Sem Terra (MST), entre outros.

Outra conquista marcante do Movimento foi a participação do Brasil na "III Conferência Mundial contra o Racismo, Discriminação Racial, Xenofobia e Intolerância Correlatas", na África do Sul, Durban, em 2000, em que um Comitê de ativistas esteve presente pressionando um posicionamento do governo brasileiro no que tange a instauração de políticas afirmativas para a população afrodescendente. A participação em Durban fez com que o Brasil firmasse o Plano de Ação de Durban, o qual representava o compromisso internacional brasileiro em desenvolver políticas antidiscriminatórias (RIBEIRO, 2013).

O governo de Luís Inácio Lula da Silva atuou no sentido de dar continuidade ao discurso de FHC reconhecendo a existência do racismo no Brasil e a necessidade de se promover políticas para combatê-lo. Ainda no Programa de Governo, foi lançado o "Programa Brasil sem Racismo", em 2002, em que se demonstra o comprometimento do governo com pautas relacionadas a políticas para a população afrodescendente. A resposta mais efetiva por parte do governo de Lula às demandas do Movimento Negro foi a criação da Secretaria Especial de Políticas de Promoção da Igualdade Racial (SEPPIR), em 2003 (RIBEIRO, 2013). A SEPPIR foi criada como órgão assessor da Presidência da República com status de Ministério e, em 2010, foi transformada em Ministério tendo "a missão de formular, articular e coordenar políticas para a superação do racismo e a promoção da igualdade racial" (RIBEIRO, 2013, p. 182).

O estatuto da igualdade Racial, proposto como projeto de Lei (PLS) pelo então Senador

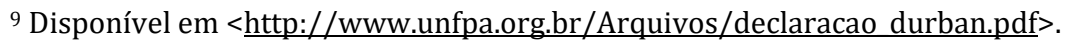


Paulo Paim em 2000, e transformado em lei ordinária em 2010 (12.288/2010), foi uma referência para ação efetiva do Estado brasileiro para a defesa dos direitos étnicos individuais e combate à discriminação. Em 2003, Lula também sancionou a lei 10.639, que estabelecia as diretrizes e bases da educação nacional para incluir no currículo oficial da Rede de Ensino a temática "História e Cultura Afro-Brasileira". Em 2004, aprovaram-se as cotas no ProUni, instituída através da Lei 11.096/05, a qual garante a reserva de vagas nos mesmos termos sociais, econômicos e de autodeclaração da Lei de Cotas nas Universidades.

A partir desses eventos, o Estado brasileiro, tanto a nível sub-nacional como federal, passou a desenvolver políticas em torno da questão racial. Uma política que merece atenção tendo em vista sua dimensão no contexto da sociedade brasileira foi a aprovação das Cotas nas Universidades (Lei 12.711). A política de iniciativa local das universidades ${ }^{10}$ se difundiu ao âmbito federal e culminou com a sanção da presidenta Dilma em 2012. A lei 12.711 teve impacto de escala nacional ao prever a garantia de reserva de $50 \%$ das vagas das universidades públicas e instituições federais a estudantes que: cursaram o ensino médio em escolas públicas; fossem oriundos de família com renda per capta de até um salário mínimo e meio; e/ou auto-declarados pretos, pardos e indígenas. Ao aprovar a Lei de Cotas, o governo brasileiro abriu um espaço às camadas historicamente marginalizadas do acesso à educação superior.

Diante do exposto, é possível entender o Movimento Negro no Brasil como um continuum. Desde as diversas agremiações e clubes criados no início do século XX até uma ação coletiva mais propositiva de mobilização em prol de demandas do Estado brasileiro. Nesse sentido, pode-se afirmar que o movimento entendido como luta contra as estruturas da democracia racial insurge a partir da década de 1970. De modo geral, podem-se assinalar alguns resultados entendidos como essenciais para compreender as posteriores conquistas, isto é, para chamar a atenção do Estado e lograr políticas públicas, são eles: o Movimento Negro Unificado e a organização da luta contra estruturas discriminatórias na sociedade brasileira; a presença do Movimento na Constituinte - que logra a criminalização do racismo como crime inafiançável; a Marcha Zumbi dos Palmares, a qual devido à ampla adesão de militantes dos mais diversos setores - resultou com o primeiro Presidente da República, FHC, reconhecendo a existência de estruturas racistas no Brasil; a presença de parlamentares negros e negras no Legislativo, engendrando propostas de políticas antidiscriminatórias, a favor da população afrodescendente; e, a participação do Brasil e de um comitê do Movimento Negro do Brasil na Conferência de Durban. Estes e outros acontecimentos ${ }^{11}$, resultaram com o desenvolvimento e implementação de políticas públicas que, de fato, passaram a

\footnotetext{
10 De 2001 a 2003 a Universidade Estadual do Rio de Janeiro (UERJ), Universidade Estadual do Norte Fluminense (UENF), Universidade do Estado da Bahia (UNEB) e a Universidade de Brasília (UnB) foram as primeiras a utilizar o sistema de reserva de vagas para ingresso em seus processos seletivos.

11 Pretendeu-se, nessa reflexão, retomar apenas eventos mais significativos que marcaram o histórico do Movimento Negro no Brasil. Todavia, se reconhece que muitos outros fatores, eventos e variáveis, em conjunto, foram capazes de mudar a conjuntura da relação do Estado brasileiro com a questão racial.
} 
reconhecer a dívida histórica que o país possui com uma população historicamente alijada de estruturas de poder econômica, social e política.

\section{CONSIDERAÇÕES FINAIS}

As revoluções ocorridas na década de 1960 e, em especial, o ano de 1968 foi salutar para o Movimento Negro em vários países do globo. Estados Unidos e Brasil são casos especiais uma vez que, apesar de sistemas distintos de segregação racial, o Movimento por igualdade de oportunidades e fim de estruturas racistas ganhou vozes e conquistou mudanças expressivas dentro das sociedades.

0 regime de segregação norte-americano era institucional, isto é, visível e regulamentado pelas leis do Estado. Neste, os negros não podiam ter acesso aos mesmos espaços que brancos. Nesse sentido, a luta por direitos civis foi mais ampla e mais aceita por diversos grupos dentro da sociedade, ainda que não sem muita resistência e ação coletiva por meio das várias organizações sociais e táticas de mobilização. O movimento de 1968 afeta a sociedade norte-americana, pois os diversos atores e organizações do Movimento Negro se negam a aceitar as estruturas sociais, políticas e culturais impostas por um Estado segregacionista. Primeiramente, a ação coletiva não violenta e os meios de comunicação são elementares para a difusão desse movimento. A frase proferida por Martin Luther King Jr., em Washington (1963), "I have a dream" foi uma sinalização de rompimento com tais estruturas. As diversas organizações culturais manifestadas na música e no orgulho negro (no "Black Power" e Black Pride) também representam o momento que 1968 propicia: uma mudança nas estruturas cognitivas. Busca-se, nesse sentido, repensar as estruturas impostas por modelos tradicionais e reivindicar a liberdade e a igualdade de oportunidades a todos os indivíduos. 0 movimento Black Power, mais subversivo e confrontador que surge posteriormente, foi motivo de preocupação ao próprio Estado norte-americano. Sua organização e sua ideologia política socialista propõe um comportamento antissistêmico, uma forma de desafiar o Estado com uma organização autônoma e nacionalista. A associação de estudantes é também um elemento presente nas Revoluções de 1968 visto que cristalizam a insatisfação dos jovens com o status quo vigente. Assim, o Movimento Negro norte-americano é pioneiro em várias táticas de protestos em busca dos direitos civis para a população afro-americana e influencia a criação de muitos outros movimentos ao redor do globo - transcende-se a luta.

No Brasil, em especial, a luta não se dá contra uma segregação institucionalizada, mas sim contra um "mito", uma ilusão criada pelas camadas dominantes para convencer a sociedade e, principalmente, a população negra que o racismo não existe aqui. Nesse sentido, as várias organizações e movimentos fundados ao longo do século XX buscam trazer a superfície esse debate e contestar essas estruturas que, apesar de não se assumirem publicamente como racialmente 
segregadoras, impediam a população afrodescendente de participar de diversos espaços na vida social, econômica e política do Brasil - o movimento não ganha adesão ampla de forma imediata, mas evolui, hiberna e eclode. 1968 se manifesta no Brasil no fim de 1970, após a abertura política do regime ditatorial, o qual calou a voz de diversos movimentos sociais. Nesse momento, o Movimento Negro reivindica para si sua negritude, de modo que termos como "homens de cor" são oficialmente abolidos. Fortemente influenciados pelos Movimentos dos Direitos Civis e Black Power dos Estados Unidos, a ação coletiva no Brasil se manifesta por meio da cultura e música, da arte e, principalmente, de contestações propositivas sobre a necessidade da criação de políticas que promovessem a igualdade de oportunidades para brasileiros afrodescendentes. Confronta-se a democracia racial. 0 movimento estudantil também se fez presente nesse contexto, visto que os jovens universitários não se conformavam com o discurso meritocrático e de democracia racial que buscava explicar a razão de tão poucos de seus similares em instituições de renome. 0 Movimento Negro Unificado é uma voz essencial na reivindicação de demandas da população negra, uma vez que é o resultado de uma mobilização social que surgiu logo após a Abolição, em 1889. Para muitos, era necessária uma Segunda Abolição: das estruturas que se mantiveram e se legitimaram para manter o negro às margens da sociedade.

Em ambos os contextos, o movimento de 1968 - que apesar da data, se inicia muito antes e torna-se um resultado explosivo de reivindicações ao longo da evolução do Movimento Negro - foi capaz de chamar a atenção para o descontentamento de camadas da sociedade que não mais aceitariam as estruturas discriminatórias. A adesão da população afrodescendente aos movimentos e protestos foi incremental para a força do movimento e, em ambos os contextos, muitas mudanças foram conquistadas não só a nível legal do Estado, mas também social e cognitivo: o negro se entende como negro e reivindica os espaços que historicamente lhe foi negado ou limitado; tem orgulho de seu cabelo, de sua música e de sua cultura e passa a desafiar as estruturas que buscaram lhe marginalizar durante toda sua existência.

\section{REFERÊNCIAS}

BIHR, Alain. Maio-junho de 1968 na França: o epicentro de uma crise de hegemonia (parte II), Dossiê: 40 anos de Maio de 68, Revista Mediações v. 13, n 102, p. 09-33, 2008.

BILYEU, Suzanne. 1960: The Greensboro Sit Ins When Four students sat down at a lunch counter in Greensboro, N.C., over 50 years ago, they helped reignite the Civil Rights Movement, s.d.

CARMICHAEL, Stokeley. "Black Power" Speech by Stokely Carmichael, former chairman of the Student Nonviolent Coordinating Committee. University of California, Berkeley, November 19,
1966. Transcrito de observações gravadas. Reimpresso do documento "Black Protest: 350 Years of History, Documents, and Analyses", Joanne Grant. Disponível em: < https://www.crmvet.org/info/stokley.htm>. Acesso em: fev. 2019.

CHURCHILL, Ward. WALL, Jim V. The COINTELPRO Papers Documents from the FBI's Secret Wars Against Dissent in the United States (Chapter 5). COINTELPRO - Black Liberation Movement, South End Press, 2002. ISBN 0-89608-359-4. 
DOMINGUES, Petrônio. Movimento da negritude: uma breve reconstrução histórica. Mediações Revista de Ciências Sociais, Londrina, v. 10, n.1, p. 25-40, jan.-jun. 2005.

. Movimento Negro Brasileiro: alguns apontamentos históricos. Revista Tempo, p. 100122, 2007.

HOLTEY, Ingrid. Re-linking Europe and the "Third World". In: A Revolution of Perception? Consequences and Echoes of 1968. British Library Cataloguing in Publication Data, Berghahn Books, 2014. ISBN 9781782383796.

HANCHARD, Michael G. Racial Democracy: Hegemony, Brazilian Style. In: Orpheus and Power: the Movimento Negro of Rio De Janeiro and São Paulo, Brazil, 1945-1988. Princeton University Press Princeton, New Jersey, 1994. ISBN 0-691-03292-0.

JOHNSON, Cedric. Revolutionaries to race leaders: Black power and the making of African American politics. University of Minnesota Press, pp. 294, 2007. ISBN 100-8166-4478-0.

JOSEPH, Peniel E. Introduction. Community Organizing, Grassroots Politics, and Neighborhood Rebels: Local Struggles for Black Power in America. In: Neighborhood rebels: Black power at the local level. PalGrave Macmillan: New York, 2010.

KURLANSKY, Mark. 1968: o ano que abalou o mundo. Tradução de Sônia Coutinho. Rio de Janeiro: José Olympio, 2005.

KATSIAFICAS, George. The Global Imagination of 1968: Revolution and Counterrevolution. Library of Congress, 2018. ISBN: 978-1-62963-439-5.
MORRIS, Aldon D. A retrospective on the Civil Rights Movement: Political and Intellectual Landmarks. Annual Reviews Sociology, n.25, p. 517-39, 1999.

NASCIMENTO, Abdias. O Genocídio do Negro Brasileiro: Processo de um racismo mascarado. Editora Paz e Terra S/A, 1978.

PEREIRA, Almilcar A. "O Mundo Negro": a constituição do movimento negro contemporâneo no Brasil (1970-1995). Tese apresentada no Programa de Pós-Graduação em História, Universidade Federal Fluminense (UFF), 2010. RIBEIRO, Matilde. Institucionalização das Políticas de Promoção da Igualdade Racial No Brasil: Percursos e Estratégias - 1986 A 2010. Tese apresentada no Programa de Serviço Social, Pontifícia Universidade Católica de São Paulo, 2013

RISSMAN, Rebecca. The Black Power movement. Library of Congress Cataloging Publication Data, Africana Studies Department, University at Albany, 2015 ROBINSON, Marc A. The black power movement and the Black Student Union (BSU) in Washington State, 1967-1970. Dissertação de Doutorado em Filosofia, Washington State University, pp. 255, 2012. SANTOS, Sales A.; SANTOS, João V. BERTÚLIO, Dora L. O processo de aprovação do Estatuto da Igualdade Racial, Lei no 12.288 , de 20 de julho de 2010. Brasília, 2011. Brasília: INESC,76 p, 2011.

WALLERSTEIN, Immanuel. ZUKIN, Sharon. 1968, Revolution in the World-System: Theses and Queries. Theory and Society, Vol. 18, No. 4 pp. 431-449, Springer Stable, 1989. Disponível em: <http://www.jstor.org/stable/657747>. Acesso em: janeiro, 2019. 